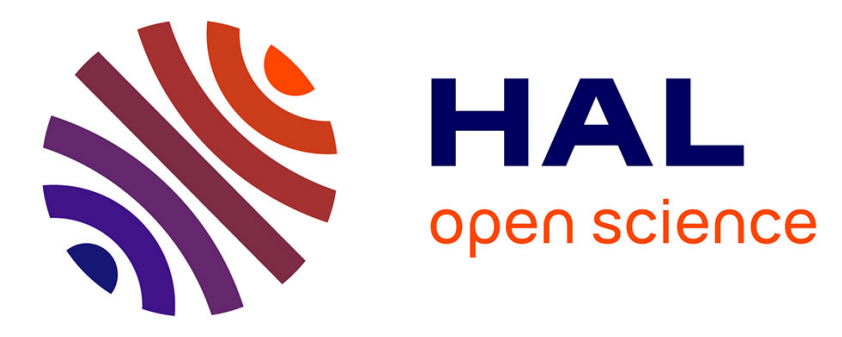

\title{
Comparison between web-based and paper versions of a self-administered anthropometric questionnaire
} Mathilde Touvier, Caroline Méjean, Emmanuelle Kesse-Guyot, Clothilde Pollet, Aurélie Malon, Katia Castetbon, Serge Hercberg

\section{- To cite this version:}

Mathilde Touvier, Caroline Méjean, Emmanuelle Kesse-Guyot, Clothilde Pollet, Aurélie Malon, et al. Comparison between web-based and paper versions of a self-administered anthropometric questionnaire. European Journal of Epidemiology, 2010, 25 (5), pp.287-296. 10.1007/s10654-010-9433-9 . hal-00570128

\section{HAL Id: hal-00570128 \\ https://hal.science/hal-00570128}

Submitted on 27 Feb 2011

HAL is a multi-disciplinary open access archive for the deposit and dissemination of scientific research documents, whether they are published or not. The documents may come from teaching and research institutions in France or abroad, or from public or private research centers.
L'archive ouverte pluridisciplinaire HAL, est destinée au dépôt et à la diffusion de documents scientifiques de niveau recherche, publiés ou non, émanant des établissements d'enseignement et de recherche français ou étrangers, des laboratoires publics ou privés. 


\title{
Comparison between web-based and paper versions of a self-administered anthropometric questionnaire
}

\author{
Mathilde Touvier · Caroline Méjean • \\ Emmanuelle Kesse-Guyot • Clothilde Pollet • \\ Aurélie Malon · Katia Castetbon · Serge Hercberg
}

Received: 7 December 2009/ Accepted: 4 February 2010/Published online: 27 February 2010

(C) Springer Science+Business Media B.V. 2010

\begin{abstract}
Online data collection could advantageously replace paper-and-pencil questionnaires in epidemiological studies by reducing the logistic burden, the cost and the duration of data processing. However, there is a need for studies comparing these new instruments to traditional ones. Our objective was to compare the web-based version of the NutriNet-Santé self-administered anthropometric questionnaire to the paper-based version. The questionnaire included 17 questions divided into subquestions (55 variables in all) dealing with height, weight, hip and waist circumferences, weight history, restrictive diet and weight self-perception. Both versions of the questionnaire were filled out by 147 volunteers (paper version first, $N=76$, or web-based version first, $N=71$ ) participating in the SU.VI.MAX ("Supplémentation en VItamines Minéraux et AntioXydants") cohort (age-range: 49-75 years; men: $46.3 \%$ ). At the end of the test, subjects filled in a "satisfaction" questionnaire giving their opinions and feelings about each version. Agreement was assessed by intraclass correlation coefficients (ICCs) and kappas. We also quantified the number of errors inherent in the paper version.
\end{abstract}

M. Touvier $(\bowtie) \cdot$ C. Méjean · E. Kesse-Guyot · C. Pollet ·

A. Malon $\cdot$ S. Hercberg

UREN (Unité de Recherche en Epidémiologie Nutritionnelle),

U557 Inserm/U1125 Inra/Cnam/Paris 13, CRNH IdF, SMBH

Paris 13, 74 rue Marcel Cachin, 93017 Bobigny, France

e-mail: m.touvier@uren.smbh.univ-paris13.fr

K. Castetbon $\cdot$ S. Hercberg

USEN (Unité de Surveillance et d'Epidémiologie

Nutritionnelle), Institut de Veille Sanitaire,

Université Paris 13, 93017 Bobigny, France

S. Hercberg

Département de Santé Publique, Hôpital Avicenne,

93017 Bobigny, France
Agreement between the two versions was high. ICCs ranged from 0.86 to 1.00 . Kappas ranged from 0.69 to 1.00 for comparable variables. A total of 82 data entry mistakes (1.5\% of total entries), 60 missing values $(1.1 \%), 57$ inconsistent values $(1.1 \%)$ and 3 abnormal values $(0.1 \%)$ were counted in the paper version (non-existent in the webbased version due to integrated controls). The web-based version was preferred by $92.2 \%$ of users. In conclusion, the quality of information provided by the web-based anthropometric questionnaire used in the NutriNet-Santé Study was equal to, or better than, that of the paper version, with substantial logistic and cost advantages.

Keywords Anthropometry - Comparative study . Internet · Self-administered $\cdot$ Web-based questionnaire

\section{Abbreviation \\ ICC Intraclass correlation coefficient}

\section{Introduction}

An increasing body of literature suggests causal relationships between diet, physical activity, overweight and adiposity, on the one hand, and several chronic pathologies such as cancers and cardiovascular diseases on the other [1-3]. However, there is still a need for carefully conducted, large prospective cohort studies involving hundreds of thousands of subjects and collecting numerous data on various potential confounding factors, in order to more thoroughly investigate and confirm such relationships. Traditional performance of these studies is complex and costly, requiring heavy logistic resources related to printing 
and mailing of paper questionnaires, as well as data entry, checking and cleaning of collected information. Studies based on telephone interviews may improve several logistic aspects, but remain very costly. Therefore, data collection via the internet might considerably facilitate the entire process and advantageously replace traditional methods in the near future [4].

The quality of collected data is also of utmost importance. Traditional paper-based questionnaires may generate data entry mistakes along with missing, inconsistent or abnormal data. The remaining inconsistencies in the nutritional epidemiology of overweight and obesity could be partly due to methodological difficulties that prevented generation of the necessary evidence. Web-based questionnaires can minimize these errors by adding automating controls and skip or branching logic.

Literature is lacking on controlled empirical studies investigating the potential for differential effects of administrative methods [5-7]. Therefore, studies showing how new instruments compare to traditional ones are of interest.

In May 2009 in France, our group launched the NutriNetSanté Study. This is the first web-based prospective cohort study worldwide on such a broad scale, as it is scheduled to include 500,000 volunteers (aged $\geq 18$ years) over the next 5 years and will investigate the relationship between intake of nutrients, food group dietary patterns, nutritional status and health (especially the risk of chronic diseases), as well as examining determinants of dietary behavior. Participants will be followed for at least 5 years via a web site specifically created for that purpose (www.etude-nutrinet-santé.fr ). All questionnaires and forms are directly filled out online (internet) using a secure HTML interface. Before launching the NutriNet-Santé cohort, we conducted test studies to compare the web-based version of baseline questionnaires to corresponding usual methods.

The objective of the present study was to compare the web-based version of the NutriNet-Santé self-administered anthropometric questionnaire with the paper-based version, by administering both versions to a sample of about 150 subjects of mature age, accustomed to filling out paper questionnaires, but who were not specifically trained web users. Our hypotheses were that (1) there would be a high agreement between the answers to the two versions and (2) the paper version would generate a substantial number of errors that could be avoided in the web-based version.

\section{Methods}

\section{Study population}

In January 2009, a call for participation was launched among subjects of the SU.VI.MAX. cohort ("Supplémentation en VItamines Minéraux et AntioXydants") both verbally (during the annual meeting of subjects) and by e-mail (collected by paper questionnaire during the SU.VI.MAX follow-up for 5,949 subjects out of 13,017). Persons who were interested in participating had to register their candidacy on a specific web-site and to provide an actualised e-mail address. A valid e-mail address and a potential access to the internet were required to participate. Before the end of January, already 1,090 persons were volunteers and were available for participating in NutriNet-Santé validation studies; thus we stopped the call for participation. Among them, 170 were randomly selected to test the anthropometric questionnaire. They were between 35 and 60 years of age at the beginning of the SU.VI.MAX. study in 1994. The design, methods and rationale of this cohort have been described elsewhere [8]. All procedures were approved by the Ethical Committee for Studies with Human Subjects and the Commission Nationale Informatique et Liberté (CNIL $\mathrm{N}^{\circ}$ 908450). Electronic informed consent was obtained from all subjects.

The NutriNet-Santé anthropometric questionnaire (web-based and paper versions)

The self-administered NutriNet-Santé anthropometric questionnaire [9] includes 17 questions divided into subquestions (55 variables in all), dealing with height, weight, hip and waist circumferences, weight history, practice of restrictive diets, weight self-perception and SorensenStunkard's silhouettes [10]. For the present test study, two versions of this questionnaire were developed: a paper version and a web-based version, used in the NutriNetSanté cohort study. The 170 subjects were asked to fill in both versions of the questionnaire. They were randomly assigned to two groups ( $N=85$ each) according to the order in which the two versions were given to them. For group 1, the paper version was given to them first (the login and password were provided to the subjects for access to the web-based version only when we had received their completed paper questionnaire by regular mail); group 2 included those who received the web-based version first (the paper version was mailed to participants when they had completed the web-based version).

In the paper version, the conditional branch was indicated by written instructions (e.g. "if yes, then go to question No. 5, and if no, go to No. 6"). In the web-based version, subjects were automatically directed to the appropriate question according to their previous answers. Besides, the web-based version did not allow missing values (all items had to be completed in order to access the next screen) and boundary logic controls were included (e.g. height had to range from 90 to $220 \mathrm{~cm}$ ). If these conditions were not respected, the subject was alerted by 
an alarm message indicating the nature of the problem and the need to correct it before going onto complete the questionnaire.

In both versions, identical written instructions, including photographs of self-measurement of weight and hip/waist circumferences, were provided to participants. In addition, in the web-based version, subjects had access to videos explaining body self-measurements and general explanations on filling out the questionnaire via the internet (e.g. how to navigate between screens and answer questions).

Data from the web-based questionnaire were directly included in our database. The answers to the paper version were captured by two independent trained keyboard operators. When an inconsistency between the two operators was detected, data were checked on the paper questionnaire and the correct answer was retained.

"Satisfaction" questionnaire

After completing the two versions of the anthropometric questionnaire, participants were requested to fill in a webbased "satisfaction" questionnaire describing their attitude toward the internet (self-evaluated computer and web knowledge, web access, type of connexion), how long it took to fill out each version, their opinion of each version (attractiveness of layout, fluency of use, etc.) and their preferred version.

\section{Statistical analyses}

Agreement between the two versions of the anthropometric questionnaire was quantified by intraclass correlation coefficients (ICCs) for the eight continuous variables [11] and kappas for 18 categorical variables [12]. For the remaining 29 categorical variables corresponding to details on restrictive diet motivation (e.g. vegetarianism, food allergies), methods used for weight reduction (e.g. use of laxatives or meal substitutes) and the ability to carry out waist and hip measurements (yes/no), kappa was not a reliable estimate for agreement because of a substantial imbalance in the table's marginal totals (for each modality, only a few participants were concerned) [12]. Thus, kappas were not presented in this paper for these variables. ICCs and kappas were calculated overall and stratified by handout order (which version was given first), age $(<$ or $\geq 60$ years), gender and web knowledge (novice/inexperienced or experienced/expert). For the self-perceived Sorensen silhouette variable, which comprised a high number of categories, weighted kappas were calculated in order to assign different weights for the closest and the most distant disparities.

Next, we quantified the number of data entry mistakes and missing, inconsistent or abnormal data inherent in the paper version (non-existent in the web-based version due to integrated controls), and we compared them between the two handout groups using binomial tests.

Third, all answers to the "satisfaction" questionnaire (time needed for filling out each version, along with the evaluation) were compared between the web-based and the paper version of the anthropometric questionnaire using Mac-Nemar $\mathrm{Chi}^{2}$ tests.

Finally, we evaluated the cost related to the paper version of the anthropometric questionnaire (printing, mailing and staff needed for data entry, non-existent in the webbased version by definition) and the cost related to the development and support of the web tool.

For all analyses, the significance level was two-sided and set at 0.05. All statistical analyses were performed using SAS software (version 9.1, SAS Institute Inc., Cary, NC, USA).

\section{Results}

Characteristics of the study population

We excluded 23 subjects from the 170 initially selected: 15 subjects did not respond despite several reminders, 5 had misunderstood the modalities of the study (e.g. necessity for web connection and for filling out two versions of the same questionnaire) and withdrew their participation, 2 had internet connection problems, and one participant stopped because he felt the web system was too complex for him. Thus, 147 subjects remained for analyses (76 completed the paper version first and 71 the web-based version first); among them, 128 subjects filled in the satisfaction questionnaire. The median number of days between filling out the two versions was 9 (minimum 2 days, maximum 61 days). Table 1 presents sociodemographic and web characteristics of the study population. We checked that randomized handout order groups were well balanced for all characteristics $(P>0.1$, data not tabulated). Participants were mature in age (mean \pm SD: $62.7 \pm 5.8$ years; age range: $49-75$ years) and about $25 \%$ considered themselves to be novices/inexperienced in computer and web use.

Agreement between the web-based and paper versions

Table 2 provides ICCs for agreement between the two versions (for quantitative variables). ICCs ranged from 0.86 to 1.00 for the eight continuous variables in the questionnaire. Table 3 provides agreement and kappas between the two versions for the main qualitative variables. Kappas calculated for 18 categorical variables ranged between 0.69 and 1.00, except for the four variables corresponding to the questions "Did you carry out this body 
Table 1 Characteristics of the study population $(N=147)$

\begin{tabular}{|c|c|c|c|c|c|c|}
\hline \multirow[b]{2}{*}{ Age (years) } & \multicolumn{2}{|c|}{ All $(N=147)$} & \multicolumn{2}{|c|}{$\begin{array}{l}\text { Paper version } \\
\text { first }(N=76)\end{array}$} & \multicolumn{2}{|c|}{$\begin{array}{l}\text { Web-based version } \\
\text { first }(N=71)\end{array}$} \\
\hline & $\begin{array}{l}\text { Mean } \\
62.7 \\
n\end{array}$ & $\begin{array}{l}\text { SD } \\
5.8 \\
\%\end{array}$ & $\begin{array}{l}\text { Mean } \\
62.4 \\
n\end{array}$ & $\begin{array}{l}\text { SD } \\
5.5 \\
\%\end{array}$ & $\begin{array}{l}\text { Mean } \\
63.0 \\
n\end{array}$ & $\begin{array}{l}\text { SD } \\
6.1 \\
\%\end{array}$ \\
\hline Female & 79 & 53.7 & 40 & 52.6 & 39 & 54.9 \\
\hline \multicolumn{7}{|l|}{ Education level } \\
\hline Elementary school & 18 & 12.2 & 11 & 14.5 & 7 & 9.9 \\
\hline Secondary school & 62 & 42.2 & 34 & 44.7 & 28 & 39.4 \\
\hline University or equivalent & 67 & 45.6 & 31 & 40.8 & 36 & 50.7 \\
\hline \multicolumn{7}{|l|}{ Occupational category $^{\mathrm{a}}$} \\
\hline Managerial staff & 55 & 37.4 & 25 & 32.9 & 30 & 42.3 \\
\hline Self-employed, farmers & 6 & 4.1 & 5 & 6.6 & 1 & 1.4 \\
\hline Intermediate professions, employees & 84 & 57.1 & 45 & 59.2 & 39 & 54.9 \\
\hline Manual workers & 1 & 0.7 & 1 & 1.3 & 0 & 0.0 \\
\hline Never employed & 1 & 0.7 & 0 & 0.0 & 1 & 1.4 \\
\hline \multicolumn{7}{|l|}{ Self-evaluated computer knowledge ${ }^{\mathrm{b}}$} \\
\hline Novice or inexperienced & 31 & 24.2 & 17 & 25.8 & 14 & 22.6 \\
\hline Experienced or expert & 97 & 75.8 & 49 & 74.2 & 48 & 77.4 \\
\hline \multicolumn{7}{|l|}{ Self-evaluated web knowledge ${ }^{b}$} \\
\hline Novice or inexperienced & 33 & 25.8 & 15 & 22.7 & 18 & 29.0 \\
\hline Experienced or expert & 95 & 74.2 & 51 & 77.3 & 44 & 71.0 \\
\hline \multicolumn{7}{|l|}{ Type of connexion ${ }^{b}$} \\
\hline$<512 \mathrm{k}$ & 36 & 28.1 & 15 & 22.7 & 21 & 33.9 \\
\hline$\geq 512$ and $<1,024 \mathrm{k}$ & 47 & 36.7 & 30 & 45.5 & 17 & 27.4 \\
\hline$\geq 1,024 \mathrm{k}$ & 36 & 28.1 & 18 & 27.3 & 18 & 29.0 \\
\hline Do not know & 9 & 7.0 & 3 & 4.5 & 6 & 9.7 \\
\hline
\end{tabular}

${ }^{a}$ Current occupation or most recent job if they were retired or unemployed

b 128 subjects ( 66 for the paper version first and 62 for the web-based version first) returned the satisfaction questionnaire, thereby providing this information

measurement specifically for this study?" (for height, weight, and hip and waist circumferences). For the four latter variables, kappas were low (e.g. 0.18 for height measurement), since many subjects answered "yes" only in the first version they had completed (and "no" in the second version). For each of the remaining 29 categorical variables, very few subjects had differing responses in the two versions (maximum 6). For each variable, kappas and ICCs were similar in all stratification groups except for weight evolution during the last 3 months and current practice of a restrictive diet, for which lower kappas were observed in subjects below 60 years of age and in women.

Data entry mistakes and missing, inconsistent or abnormal data inherent in the paper version

Corresponding numbers are presented in Table 4. Most of the missing data (i.e. no information for the variable; no numeric value provided, nor "I do not remember" box checked) consisted of age at maximal and minimal weight (missing for eight subjects, i.e. 5.4\% of the study population) and these maximal and minimal weights themselves (missing for 6 subjects, i.e. $4.1 \%$ of the study population) (data not tabulated). Similarly, most of the inconsistent data involved the age at minimal (17) and maximal (14) weights, and the minimal (8) and maximal (5) weights themselves (the "I do not remember" box was checked and a numeric value was also provided).

Duration, satisfaction and cost

Within the 128 subjects who completed the "satisfaction questionnaire", although the time needed to fill out the questionnaires was comparable for the two versions, the web-based version was considered more satisfactory than the paper version (Table 5). The web-based version was preferred by $92.2 \%$ of the subjects (data not tabulated). About $87.5 \%$ of participants filled out the web-based questionnaire in one sitting. About $74.2 \%$ consulted the "recap form", which provides a concise summary of all 


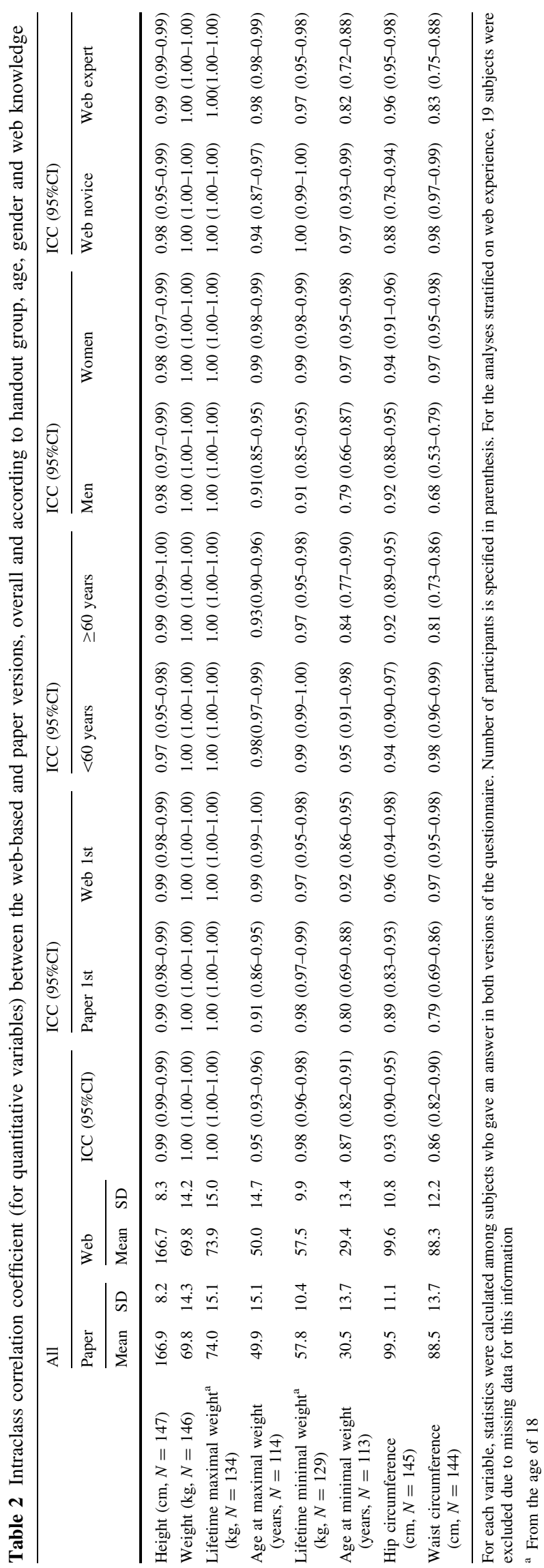

answers to the questionnaire. Among them, $18.8 \%$ declared that it helped them to detect a mistake and correct it. About $94.5 \%$ of the participants felt that the web-based interface was user-friendly, while $88.3 \%$ appreciated the "mid-questionnaire support message". Only 29 subjects $(22.7 \%)$ viewed the help video; all of them were entirely or fairly satisfied.

Once conceptually designed, the elaboration of the paper version of the questionnaire (writing and editing) took only 1 day. Cost specific to the paper version involved: printing of the questionnaire $(0.025 €$ /printed page; hence 0.18 $€ /$ subject), mailing it to the participants (1.67 €/subject), payment of mailing costs for returning the completed questionnaire $(1.71 € /$ subject + a package cost, for the entire cohort, for postal service enabling free mailing by the subjects: $460 €$ the 1 st year, and then $445 € / y)$ and cost for double data entry ( $6.38 € /$ subject, calculated on the basis of the cost for one full-time equivalent: $1913 € /$ month, including charges); this corresponded to a total of $9.94 €$ (14.1 US\$) for one subject and 4,965,833 € (7,052,383 US\$) for a cohort of 500,000 subjects (i.e. the targeted effective for the NutriNet-Santé study). Cost specific to the web-based version was much lower, as it involved only developmental and support cost for the study web-site. Such cost depends on technical skills and resources of implicated research teams and on standards of the product (in terms of user-friendliness, security level, quality of graphic design, etc.). Cost for our web-based tool, developed by professional web-designers, amounted to 150,000 $€(213,000$ US\$; 9 months of development) for the entire NutriNet-Santé study (and not only for the baseline anthropometric questionnaire). It comprised the whole study process: secure inscription system, development and administration of baseline questionnaires, monitoring of the cohort (e-mails to the subjects, newsletter, etc.), equipment and hosting. Cost for an additional questionnaire equivalent to the anthropometric questionnaire would cost about 5,000 $€$ (7100 US\$; 4 days of development).

\section{Discussion}

Our baseline hypothesis was confirmed: agreement between the two versions of the anthropometric questionnaire was high. Moreover, even with an overall short and simple questionnaire such as that evaluated in the present study, errors (data entry mistakes and missing, inconsistent or abnormal values) observed in the paper version were avoided in the web-based version due to automatic controls. Finally, the web-based version was highly appreciated and led to considerable logistic cost savings.

Earlier studies had compared web-based versus paper questionnaires in diverse fields such as diet [13], 


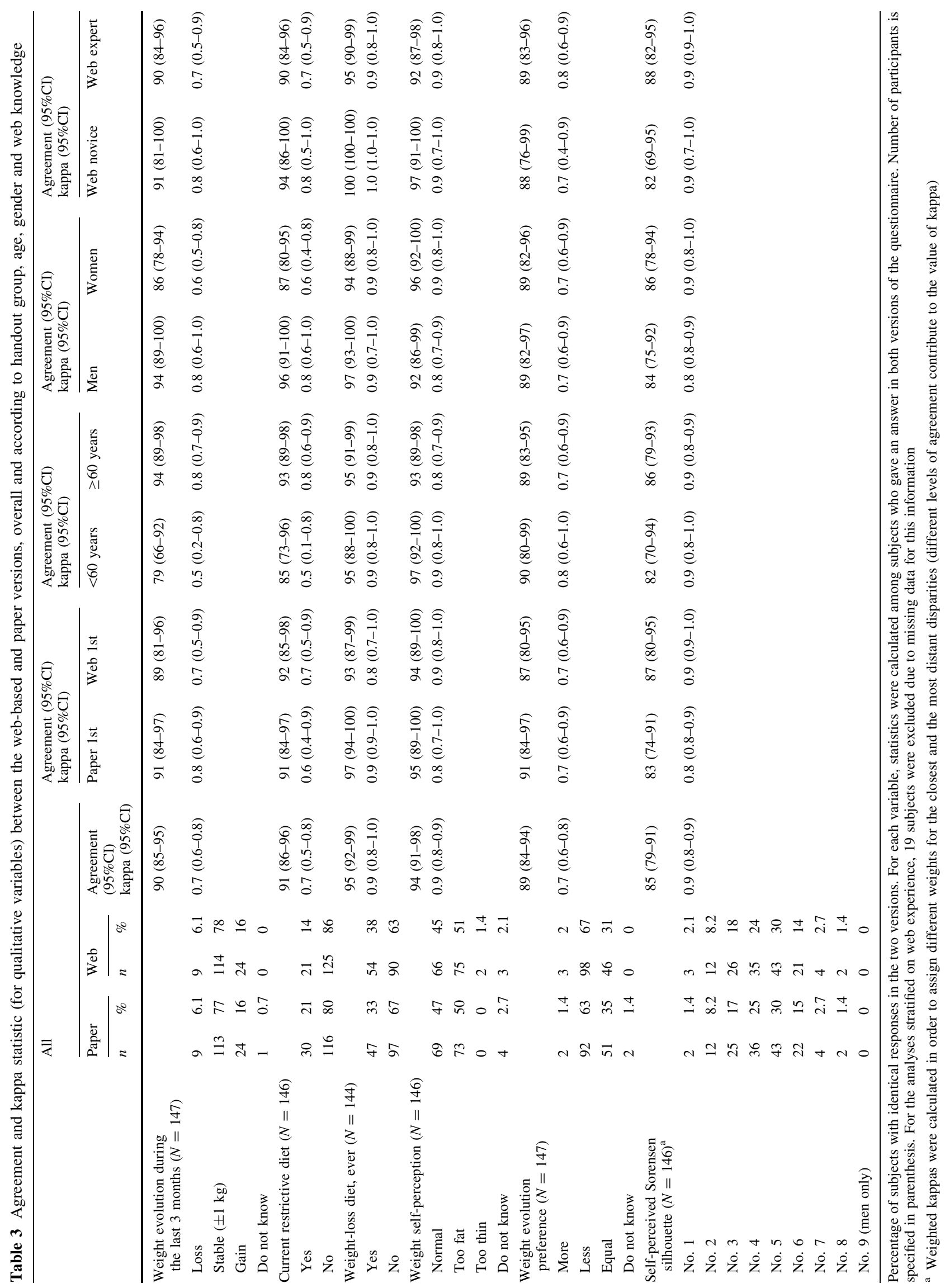


Table 4 Number of data entry mistakes and missing, inconsistent or abnormal data inherent in the paper version (for the 55 variables of the NutriNet-Santé anthropometric questionnaire)

\begin{tabular}{|c|c|c|c|c|c|c|c|}
\hline & \multicolumn{2}{|c|}{ All $(N=147)$} & \multicolumn{2}{|c|}{$\begin{array}{l}\text { Paper version } \\
1 \text { st }(N=76)\end{array}$} & \multicolumn{2}{|c|}{$\begin{array}{l}\text { Web-based version } \\
1 \text { st }(N=71)\end{array}$} & \multirow[t]{2}{*}{$P^{\mathrm{a}}$} \\
\hline & Number & $\%^{\mathrm{b}}$ & Number & $\%$ & Number & $\%$ & \\
\hline \multicolumn{8}{|l|}{ Number of data entry mistakes } \\
\hline Keyboard operator No. 1 & 102 & 1.9 & 56 & 2.1 & 46 & 1.8 & 0.4 \\
\hline Keyboard operator No. 2 & 61 & 1.2 & 30 & 1.1 & 31 & 1.2 & 1.0 \\
\hline Mean & 81.5 & 1.5 & 43 & 1.6 & 38.5 & 1.5 & 0.5 \\
\hline $\begin{array}{l}\text { Mean number of subjects with at least } \\
\text { one data entry mistake }(\%)\end{array}$ & $52(35.4)$ & & $27.5(36.2)$ & & $24.5(34.5)$ & & 0.6 \\
\hline Number of missing values & 60 & 1.1 & 24 & 0.9 & 36 & 1.4 & 0.2 \\
\hline $\begin{array}{l}\text { Number of subjects with at least } \\
\text { one missing value }(\%)\end{array}$ & $16(10.9)$ & & $7(9.2)$ & & $9(12.7)$ & & 0.8 \\
\hline Number of inconsistent data ${ }^{c}$ & 57 & 1.1 & 28 & 1.1 & 29 & 1.1 & 1.0 \\
\hline $\begin{array}{l}\text { Number of subjects with at least } \\
\text { one inconsistent data }(\%)\end{array}$ & $31(21.1)$ & & $16(21.1)$ & & $15(21.1)$ & & 1.0 \\
\hline Number of abnormal data ${ }^{\mathrm{d}}$ & 3 & 0.1 & 2 & 0.1 & 1 & 0.0 & - \\
\hline $\begin{array}{l}\text { Number of subjects with at least } \\
\text { one abnormal data }(\%)\end{array}$ & $3(2.0)$ & & $2(2.6)$ & & $1(1.4)$ & & - \\
\hline
\end{tabular}

${ }^{a} P$ value for the difference between the two handout groups, from binomial tests

b Percentages of errors out of the number of total entries overall $=5,269$ entries (2,656 in the group "paper version 1st" and 2,613 in the group "web-based version 1st"), with a mean of 35.8 entries per subject (the number of entries varies across subjects, depending on the conditional branch)

${ }^{c}$ When information provided was inconsistent with skip or branching logic, e.g., when a subject indicated a numeric value for minimal weight reached during his/her lifetime and also checked the "I do not remember" box

${ }^{\mathrm{d}}$ When information fell outside of accepted boundaries: 1 subject declared a body weight outside of the 35-200 kg range; 1 subject declared a height outside of the 90-220 cm range; and 1 subject declared an age for minimal weight outside of the 18-120 year range

osteoporosis prevention [14] and acute mountain sickness [15]. In such pilot/validation studies involving small sample sizes, even a few misclassifications could lead to substantial variations in kappa values, thus making it meaningless to precisely compare the levels of agreement across studies. In general, however, the authors of those investigations [13-15] consistently confirmed strong agreement between the two versions. The research team of A Schatzkin (National Cancer Institute, USA) is currently undertaking detailed evaluation studies so as to compare their new web-based dietary and physical activity questionnaires to traditional methods and biomarker data [7].

A key question in large-scale internet-based studies concerns their capacity to reach a sufficiently broad and diversified population. Although use of computer-based questionnaires may exclude segments of the population without access to, or the capacity to use, computers (notably the elderly [16]), internet access is constantly increasing throughout the world and within most sociodemographic groups. France had 33 million internet users in February 2009 [17], and ranks first in the European classification for internet use according to the European Interactive Advertising Association [18]. Around 62\% of the population over the age of 11 connected to the net in a 1-month period [18]. $29 \%$ of internet users belong to low social classes [19] and one internet user in four is over 55 years of age [18]. In Europe, 178 million persons go online each week and over half $(55 \%)$ of internet users go online every day [18]. In the United States, internet use rose to $73.9 \%$ by June of 2009 [20]. More than half of persons aged 64 or older go online at least once a month [21]. This increasing internet use provides an attractive option for large-scale prospective cohort studies in developed countries.

Although online data collection may not solve traditional problems faced for reaching the population sample [22], several studies argue in favor of high acceptability and feasibility of web-based questionnaires [23-25]. Moreover, the latter, particularly usable for analytical studies that focus on associations between variables [26], have major advantages. First, data quality is positively impacted, since missing, inconsistent or abnormal data can be minimized by adding alerts to users and automated skip or branching logic. These improvements are even more effective for questions dealing with the past, such as those concerning lifetime maximal and minimal weight. Overall, percentages of errors observed in our study were low, but absolute numbers of mistakes and percentages of subjects 
Table 5 Comparison of completion time and satisfaction between the web-based and paper versions of the NutriNetSanté anthropometric questionnaire
Among the 128 subjects who returned the satisfaction questionnaire

a $P$ value for the difference between the two versions, from Bowker's test of symmetry for completion time and from MacNemar $\mathrm{Chi}^{2}$ tests for other variables

b Data missing for 1 subject out of 128

\begin{tabular}{|c|c|c|c|c|c|}
\hline & \multicolumn{2}{|c|}{ Paper version } & \multicolumn{2}{|c|}{ Web-based version } & \multirow[t]{2}{*}{$P^{\mathrm{a}}$} \\
\hline & $N$ & $\%$ & $N$ & $\%$ & \\
\hline Completion time needed & & & & & 0.07 \\
\hline$<5 \min$ & 19 & 14.8 & 22 & 17.2 & \\
\hline $5-9 \min$ & 32 & 25.0 & 41 & 32.0 & \\
\hline $10-14 \min$ & 38 & 29.7 & 35 & 27.3 & \\
\hline$\geq 15 \mathrm{~min}$ & 39 & 30.5 & 30 & 23.4 & \\
\hline Completion time was acceptable & & & & & 0.02 \\
\hline Agree & 114 & 89.1 & 124 & 96.9 & \\
\hline Disagree & 14 & 10.9 & 4 & 3.1 & \\
\hline Completion time is not a barrier for participation & & & & & 0.003 \\
\hline Agree & 114 & 89.1 & 126 & 98.4 & \\
\hline Disagree & 14 & 10.9 & 2 & 1.6 & \\
\hline Filling out this questionnaire was easy ${ }^{\mathrm{b}}$ & & & & & 0.046 \\
\hline Agree & 122 & 96.1 & 126 & 99.2 & \\
\hline Disagree & 5 & 3.9 & 1 & 0.8 & \\
\hline The questionnaire is nicely presented ${ }^{\mathrm{b}}$ & & & & & 0.05 \\
\hline Agree & 116 & 91.3 & 123 & 96.9 & \\
\hline Disagree & 11 & 8.7 & 4 & 3.1 & \\
\hline I liked this version ${ }^{\mathrm{b}}$ & & & & & 0.0002 \\
\hline Agree & 105 & 82.7 & 123 & 96.9 & \\
\hline Disagree & 22 & 17.3 & 4 & 3.1 & \\
\hline Consultation of the "Help" section ${ }^{\text {b }}$ & & & & & 0.7 \\
\hline $\begin{array}{l}\text { Yes ( } n \text { or } \% \text {, as appropriate, of subjects } \\
\text { entirely or fairly satisfied) }\end{array}$ & $58(54)$ & $45.7(93.1)$ & $55(54)$ & $43.3(98.2)$ & \\
\hline No & 69 & 54.3 & 72 & 56.7 & \\
\hline
\end{tabular}

with at least one error were not negligible. Besides, this questionnaire is very simple in terms of conditional branch and type of information requested. Thus, one could expect a much higher percentage of mistakes in a more complicated questionnaire. Second, the study burden is lowered for participants, who can complete their questionnaires via a user-friendly interface that provides interactive help tools (such as videos and animated screens). Indeed, in our study, we observed that time needed for completion was less frequently viewed as a constraint with the web-based version than with the paper version. This could be partly explained by the convivial easy-to-use nature of the webbased questionnaire. Third, even in non-anonymous surveys, internet introduces a distance between the investigator and the subject, thereby encouraging the latter to deliver uncensored personal information [27]. This is particularly important for sensitive questions related to weight status, body shape and self-perception, and to other topics such as use of alcohol, tobacco or other substances [28]. However, a recent study observed differences in underreporting of dietary intake by gender and weight status using a web-based survey, similar to observations made using paper-based $24 \mathrm{~h}$ recalls and dieticians' interviews [29].
Fourth, data processing is greatly facilitated, and reliability is increased by eliminating data entries or scanning of paper forms. Fifth, there is a considerable reduction in expenses and paper waste in web-based studies, since printing, mailing and treatment of paper questionnaires are avoided. Eventually, web-based studies also enable further reduction in cost when modifying the questionnaires over time, along with a high flexibility.

Whether web- or paper-based, our anthropometric questionnaire remains self-administered, which provides potentially biased information on body measurements compared to those taken by a trained interviewer [30]. However, in large cohorts such as the NutriNet-Santé Study (500,000 subjects), body measurements by interviewers would be extremely complex and costly. Nevertheless, validation of self-reported anthropometric data by objective measurements will be possible on subsamples of the cohort, providing an evaluation of the bias associated with self-reported data.

Our study had several limitations. First, paper-based questionnaires cannot represent the gold standard for their internet-based counterparts [31]. Therefore, our study was comparative rather than being a validation study using 
paper as the gold standard. Second, in this type of study, for certain variables, comparisons between the two versions are impossible or very difficult, since questions do not refer to the same period of time (e.g. weight evolution during the last 3 months). Moreover, lack of interest on the part of participants when completing the second version may affect their answers. Changes can also occur between the periods of completion of the two versions. For instance, lower kappas observed in weight evolution and current restrictive diet among subjects under 60 and among women may be explained by a new restrictive diet begun by some participants between completion of the two versions of the questionnaire. Finally, our participants belonged to middle/ high education and occupational categories; thus, caution is required when extrapolating our results to the general population, and especially to people of a low socioeconomic status. However, one-fourth of the subjects were internet novices or inexperienced, mean age was relatively high (62.7 years) and participants were accustomed to filling out paper but not web-based questionnaires (they had filled in more than 25 different paper questionnaires during their participation in the SU.VI.MAX cohort), which would tend to penalize the web-based version.

In conclusion, our study supports the idea that webbased questionnaires provide information of equal or superior quality when compared to the paper-based method, with substantial logistic and cost advantages. More studies are needed in order to find out about acceptance and validity of web-based questionnaires in not welleducated subjects, manual workers, and never-employed individuals, and in subjects that are not trained in filling out questionnaires. Online surveys are able to access wide and diversified populations and achieve quick returns. Their use should increase worldwide, with appropriate adaptation of web-based tools to country-specific cultural aspects [7]. This will advance our understanding of the relationship between anthropometry and health outcome. The internet also promises a new generation of tools for public health improvement [32], such as e-learning [33], nutritional education [34] and lifestyle counselling [35] in the field of weight management and health in general.

Acknowledgments We thank the scientists, dieticians, technicians and assistants who helped to carry out the NutriNet-Santé test studies, and all dedicated and conscientious volunteers. We especially thank Soizic Gueho (data manager) for performing statistical analysis and Gwenael Monot (computer scientist), who is coordinating the computer aspects of the NutriNet-Santé Study. We thank Voluntis (a healthcare software company) for developing the NutriNet-Santé web-based interface according to our guidelines. We are grateful to Jerri Bram for English editing of the manuscript. This work was supported by the Ministère de la Santé (DGS, French Ministry of Health); the Institut de Veille Sanitaire (InVS); the Institut National de Prévention et d'Education pour la Santé (INPES); the Fondation pour la Recherche Médicale (FRM); the Institut National de la Santé et de la Recherche Médicale (Inserm); the Institut de Recherche en Santé Publique (IRESP); the Institut National de la Recherche Agronomique (Inra); the Conservatoire National des Arts et Métiers (CNAM); and Paris 13 University.

\section{References}

1. American Institute for Cancer Research/World Cancer Research Fund. Food, nutrition, physical activity and the prevention of cancer: a global perspective. Washington, DC: American Institute for Cancer Research; 2007.

2. World Health Organization. Diet, nutrition and the prevention of chronic diseases. Joint WHO/FAO expert consultation. WHO Technical Report Series. Geneva: WHO; 2003.

3. World Health Organization. The challenge of obesity in the WHO European Region and the strategies for response. Copenhagen: WHO Regional Office for Europe; 2007.

4. Ekman A, Litton JE. New times, new needs; e-epidemiology. Eur J Epidemiol. 2007;22(5):285-92.

5. Hardré PL, Crowson HM, Xie K, Ly C. Testing differential effects of computer-based, web-based and paper-based administration of questionnaire research instruments. Br J Educ Technol. 2007;38(1):5-22.

6. Reips UD. Standards for internet-based experimenting. Exp Psychol. 2002;49(4):243-56.

7. Schatzkin A, Subar AF, Moore S, Park Y, Potischman N, Thompson FE, et al. Observational epidemiologic studies of nutrition and cancer: the next generation (with better observation). Cancer Epidemiol Biomarkers Prev. 2009;18(4):1026-32.

8. Hercberg S, Preziosi P, Briancon S, Galan P, Triol I, Malvy D, et al. A primary prevention trial using nutritional doses of antioxidant vitamins and minerals in cardiovascular diseases and cancers in a general population: the SU.VI.MAX study-design, methods, and participant characteristics. SUpplementation en VItamines et Mineraux AntioXydants. Control Clin Trials. 1998; 19(4):336-51.

9. NutriNet-Santé questionnaires [in French]. Internet: http://media. etude-nutrinet-sante.fr/questionnaires/questionnaires_nutrinet_ papier.zip (accessed 15 September 2009).

10. Sorensen TI, Stunkard AJ, Teasdale TW, Higgins MW. The accuracy of reports of weight: children's recall of their parents' weights 15 years earlier. Int J Obes. 1983;7(2):115-22.

11. Shrout PE, Fleiss JL. Intraclass correlations: uses in assessing rater reliability. Psychol Bull. 1979;86(2):420-8.

12. Feinstein AR, Cicchetti DV. High agreement but low kappa: I. The problems of two paradoxes. J Clin Epidemiol. 1990;43(6): 543-9.

13. Beasley JM, Davis A, Riley WT. Evaluation of a web-based, pictorial diet history questionnaire. Public Health Nutr. 2009; 12(5):651-9.

14. Marsden J, Jones RB. Validation of Web-based questionnaires regarding osteoporosis prevention in young British women. Health Bull (Edinb). 2001;59(4):254-62.

15. Beidleman BA, Muza SR, Fulco CS, Rock PB, Cymerman A. Validation of a shortened electronic version of the environmental symptoms questionnaire. High Alt Med Biol. 2007;8(3):192-9.

16. Klovning A, Sandvik H, Hunskaar S. Web-based survey attracted age-biased sample with more severe illness than paper-based survey. J Clin Epidemiol. 2009;62(10):1068-74.

17. Médiamétrie. Internet: http://www.mediametrie.fr/internet/ (accessed 15 September 2009).

18. European Interactive Advertising Association. Internet: http:// eiaa.net/index.asp (accessed 15 September 2009). 
19. Ipsos Media. Internet: http://www.ipsos.fr/canalipsos/poll/8273.asp/ (accessed 15 September 2009).

20. Internet World Stats (C) Copyright 2009, Miniwatts Marketing Group. Internet: http://internetworldstats.com/ (accessed 15 September 2009).

21. Golvin CS, Schadler T. The state of consumers and technology: benchmark 2008. Cambridge: Forrester Research; 2008.

22. Lefever S, Dal M, Matthiasdottir A. Online data collection in academic research: advantages and limitations. Br J Educ Technol. 2007;38(4):574-82.

23. Bexelius C, Honeth L, Ekman A, Eriksson M, Sandin S, BaggerSjoback D, et al. Evaluation of an internet-based hearing testcomparison with established methods for detection of hearing loss. J Med Internet Res. 2008;10(4):e32.

24. Ekman A, Dickman PW, Klint A, Weiderpass E, Litton JE. Feasibility of using web-based questionnaires in large populationbased epidemiological studies. Eur J Epidemiol. 2006;21(2):10311.

25. Kendler KS, Myers J, Potter J, Opalesky J. A web-based study of personality, psychopathology and substance use in twin, other relative and relationship pairs. Twin Res Hum Genet. 2009;12(2): $137-41$.

26. Etter JF, Perneger TV. A comparison of cigarette smokers recruited through the internet or by mail. Int J Epidemiol. 2001; 30(3):521-5.

27. Joinson A. Social desirability, anonymity, and Internet-based questionnaires. Behav Res Methods Instrum Comput. 1999;31(3): 433-8.
28. Wang YC, Lee CM, Lew-Ting CY, Hsiao CK, Chen DR, Chen WJ. Survey of substance use among high school students in Taipei: web-based questionnaire versus paper-and-pencil questionnaire. J Adolesc Health. 2005;37(4):289-95.

29. Vance VA, Woodruff SJ, McCargar LJ, Husted J, Hanning RM. Self-reported dietary energy intake of normal weight, overweight and obese adolescents. Public Health Nutr. 2009;12(2):222-7.

30. Rowland ML. Self-reported weight and height. Am J Clin Nutr. 1990;52(6):1125-33.

31. van der Lei J, Sturkenboom M. Of new times, new opportunities, and old problems. Eur J Epidemiol. 2007;22(5):281-3.

32. Underbakke G, McBride PE, Spencer E. Web-based resources for medical nutrition education. Am J Clin Nutr. 2006;83(4): 951S-5S.

33. Tse MM, Choi KC, Leung RS. E-health for older people: the use of technology in health promotion. Cyberpsychol Behav. 2008;11(4):475-9.

34. Brug J, Oenema A, Campbell M. Past, present, and future of computer-tailored nutrition education. Am J Clin Nutr. 2003; 77(4 Suppl):1028S-34S.

35. van Wier MF, Ariens GA, Dekkers JC, Hendriksen IJ, Smid T, van Mechelen W. Phone and e-mail counselling are effective for weight management in an overweight working population: a randomized controlled trial. BMC Public Health. 2009;9:6. 